\title{
Bonhoeffer and the Anthropocene
}

\author{
NGTT DEEL 55, SUPPLEMENTUM 1, 2014
}

\section{Rasmussen, Larry}

Union Theological Seminary, New York

\section{ABSTRACT}

Anew geologic epoch, the Anthropocene, seems to be emerging. It is the result of humanity becoming the single most powerful force of planetary nature itself. A re-reading of Bonhoeffer, from 1932 through the prison letters, uncovers his premonitions of Anthropocene reality, together with its human causes. 1) An aggressive Western war-and-industry identity alienated from nature and fuelled by mastery that knows no limits as undertaken by autonomous humans in the name of freedom without constraint has accompanied, even driven, and gravely expanded human knowledge and power. 2) The reach of this human knowledge and power upon all earthly life has strained our ethical concepts to the breaking point. This sets in motion the need to reconceive moral responsibility itself. 3) There is no dialling back of history to some previous age, including the age of a religious a priori and the God of religion. For Christians, this means the constructive work entails deep interrogation of faith's essential base points - Who is God? What do we really believe such that we would stake our lives on it? Who is Jesus Christ for us today when "today" is another epoch, even a non-analogous one? 4) In an epoch where "everything depends on humankind," the constructive work of faith and the experience of Jesus Christ will be this-worldly and Earth-honouring. Transcendence, indeed

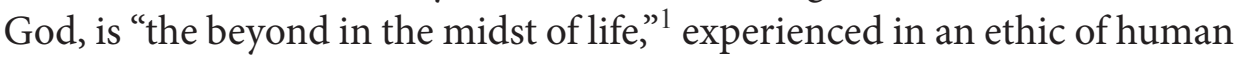
responsibility for "the whole of earthly life."

\section{KEYWORDS}

Anthropocene, Holocene, Climate change, War-and-industry identity, Worldcome-of-age, Moral responsibility, Natural life, Human knowledge and power

1 DBWE 8:367.

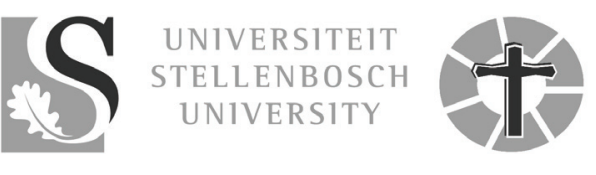




\section{CONTACT DETAILS}

Prof Rasmussen, Larry

Reinhold Niebuhr

Professor Emeritus of Social Ethics,

Union Theological Seminary, New York

lrryrasmussen@yahoo.com 
The International Commission on Stratigraphy (ICS) is the official keeper of geological time. To map Earth's ages the ICS plants what it calls "golden spikes" where geological epochs begin and end.

The notion that Earth has discontinuous ages is quite recent. Typical instead is a biblical sense of Earth time: no fossils appear in the biblical record and even the beginning of beginnings finds God creating domestic animals for a settled existence of herders and farmers. This omits dinosaurs, mastodons, and ninety-five percent of human history (hunter-gatherer), to say nothing of Earth's long tenure well before any life forms, even single-celled creatures. Thus it was against the grain of both religion and science that Jean-Leopold-Nicholas-Frederic (Georges) Cuvier (1769 - 1832) argued from his Paris fossil collection that worlds previous to ours existed. "Life on earth has often been disturbed by terrible events," he wrote in the early 1800 s, "Living organisms without number have been the victims of these catastrophes." Nature had changed course, with devastating effect. Cuvier had exposed what no one expected - a history of mass extinction on an Earth given to periodic seizures.

The ICS will decide in 2016 about whether to plant a new golden spike. If it does, that will officially signal the end of the "Holocene" (Greek for "Wholly Recent"). Please note: for geologists, given as they are to a patient sense of time, this decision isn't casual or precipitous. It means they have already accumulated sufficient evidence to deem the emergence of a new epoch worthy of a decisive judgment soon.

Meanwhile many scientists are not waiting. Climatologist Paul Crutzen interrupted a meeting that kept mentioning the eleven and a half thousand year old Holocene as our habitat by exclaiming, "Let's stop [this]. "We are no longer in the Holocene; we are in the Anthropocene." "The Anthropocene" (from anthropos, Greek for human) became the coffee break buzz, and, after Crutzen's essay, "Geology of Mankind," was published in Nature in 2002, it became the popular topic of numerous scientific journals. That human impacts are now orders of magnitude beyond what they were prior to the Industrial Revolution are not doubted anywhere. The only question is, are these geological-scale events a dramatic turn of the late Holocene or the onset of a new epoch? Should the ICS hammer in a new golden spike or not?

The International Geosphere - Biosphere Programme has also rendered its verdict. "The planet is now dominated by human activities," they said in a 2004 volume that, like Crutzen and friends, announces the Anthropocene. "Evidence from several millennia shows that the magnitude and rates of human-driven changes to the

2 Elizabeth Kolbert, 2013. “The Lost World," Part Two. The New Yorker, December 23 \& 30: 50 . 
global environment are in many cases unprecedented. There is no previous analogue for the current operation of the Earth system."3

In this case, "there is no previous analogue" means that, for the very first time, human time has merged with geological time with sufficient impact to initiate a world unlike any previous one. The "thread of operations [of previous nature] has been broken" and nature has "changed course." (Cuvier) (To see this in graph form, see pages 56-57 of Rasmussen, Earth-Honouring Faith.)

The point is that while Earth has seen wildly varied ages before, and will again before it becomes the cinder of an aging star, Homo sapiens civilization has occupied one age only. Our tenure is strictly Holocene. All recorded human history and all human civilizations to date, bar none and starting with neo-lithic settlements, have enjoyed the Holocene's emblem of a warm period of sufficient climate stability to allow, even foster, the triumph of life amid nature's on-going predilection for fluctuation, change, and an adventuresomeness that will try anything once, including big as well as little ice ages. ${ }^{4}$

Presently, however, the climate stability of the Holocene is apparently giving way to the climate volatility of the Anthropocene. The specific cause was never intended and is quite startling; namely, humankind has taken to regulating solar radiation and re-engineering Earth's surface processes. By burning dirty fuels on a massive scale, since 1950 especially but steadily from 1750 onward, we are resetting the planet's thermostat and altering the core dynamics of the atmosphere, oceans and landmasses. One result is a dramatic carbon spike and climate volatility. Present CO2 levels in the atmosphere exceed those of the last 650,000 years. ${ }^{5}$

Of utmost import for theology and ethics is that climate change and mass extinction this time around is anthropogenic geophysical change that goes where human agency and responsibility have never before gone; namely, "cumulatively across generational time, aggregately through ecological systems, and non-intentionally over evolutionary futures." We have no ethic on the books or in existing moral

3 WL Steffen et. al, Global Change and the Earth System (Berlin and New York: Springer, 2004), v.

4 “The Holocene," University of California Museum of Paleontology, http://www.ucmp. berkeley.edu.

5 Nicholas Kristoff 2014. "Neglected Topic" Winner: Climate Change. The New York Times Sunday Review, January 19:11, reporting data from William Nordhaus's new book, The Climate Casino.

6 Willis Jenkins, The Future of Ethics: Sustainability Social Justice, and Religious Creativity (Georgetown University Press, 2013), 1. 
theory that assigns responsibility in keeping with such far-flung consequences of human action.

In this setting I turn to Bonhoeffer for two reasons. 1) His project was to craft an ethic of responsibility for what he came to regard as an emerging new age. 2) His thoughts about that age, and an ethic fitted for it, are uncanny premonitions of the Anthropocene.

His own question in the prison letters can guide us. "What keeps gnawing at me is the question, what is Christianity, or who is Christ actually for us today?" $\mathrm{Or}$, in another letter, "The question is Christ and the world that has come of age." 8 But the narrative begins elsewhere.

A little-known address, "The Right to Self-Assertion," was given at the College of Technology in Berlin in 1932. There Bonhoeffer argues that European-American civilization commands a war-and-industry identity. "The era of the machine" and wars, or "wars and factories," are the West's chief means of collective assertion and problem solving. ${ }^{9}$

The source of this aggressive identity is found, he says, in battles "to master nature, fight against it, to force it to [Western human] service." This assertive human mastery over nature is no less than "the fundamental theme of European-American history." ${ }^{10}$ It leaves Western civilization fragmented from the rest of nature in its core consciousness.

Ten years later Bonhoeffer continues, now in an effort to write an ethic for the postwar period. Here, in "Heritage and Decay," a portion of the work-in-progress, Ethics, and dated 1941-42, he describes the kind of technology that emerged in the modern West. It is no longer essentially "a matter of handicraft" that, in other contexts, served "religion, royalty, culture, and people's daily needs." Modern technology has freed itself so that its "essence is not service but mastery, mastery over nature. A wholly new spirit has produced it, the spirit of violent subjugation of nature to thinking and experimenting human beings ... It has its own soul; its symbol is the machine, the embodiment of violation and exploitation of nature ... The benefits of technology pale beside its demonic powers." ${ }^{11}$

\footnotetext{
7 “Letter of 30 April, 1944," DBWE 8:362.

8 “Letter of 8 June, 1944," DBWE 8:428.

9 DBWE 11, 251.

10 DBWE 11, 252. The emphasis is mine.

11 DBWE 8:116.
} 
Later, in prison, Bonhoeffer picks up the 1932 and 1941-42 theme again, this time for a new work. Excited about his insights on an emerging era, he abruptly pauses in his work on Ethics for an undertaking that must rethink everything, the fundamental base points of Christian faith included. Unfortunately only the outline survives. The remainder was apparently the victim of his own enthusiasm; the hand-written manuscript was one of the few possessions he took with him to the Gestapo prison where it was lost in the chaos of the final year of the war.

The new work's outline, while repeating the 1932 and 1941-42 theme, is now tied to prison insights on the "world come of age." (More on that shortly.) Bonhoeffer's summary is so compact that I cite it in full:

... [The West's] goal is to be independent of nature. Nature used to be conquered by the soul; with us it is conquered through technological organization of all kinds. What is unmediated for us, what is given, is no longer nature but organization. But with this protection from the menace of nature, a new threat to life is created in turn, namely, through organization itself. Now the power of the soul is lacking! The human being is thrown back on his own resources. He has learned to cope with everything except himself. He can insure himself against everything but other human beings. In the end it all comes down to the human being. ${ }^{12}$

With the West's aim to be independent of nature and substitute the built environment ("organization") as our own tailored cosmos and preferred habitat; and with everything now, in a world of greatly increased human knowledge and power, depending upon humankind; and with this new world lacking the "spiritual force" for responsibly handling this growing technological and organizational power affecting all nature, the theological-ethical question comes to this: how to "claim Christ for a world coming of age." That is, how do we forge a viable Christian faith and ethic of responsibility for an epoch of unprecedented power across the whole of earthly life? This becomes Bonhoeffer's prison preoccupation. It reaches beyond his analysis in Ethics, ${ }^{13}$ even though the goal there was also a viable ethic of responsible action (for the post-war world).

His new line of thought is a vivid intimation of Anthropocene moral reality: Everything turns on collective human power and responsibility, the very power that has effected an ocean-spanning, Euro-American civilization fundamentally

12 "Outline for a Book," Letters and Papers from Prison, DBWE 8:500.

13 There are numerous references in the letters. Here see the "Outline for a Book," in DBWE 8, 499-504. 
fractured from nature in its consciousness, cosmology, and day-to-day life. Moreover, this war-and-industry civilization discovers that its own spiritual-moral resources for addressing its alienated powers are found wanting. If Bonhoeffer is to complete the Ethics - that is his desire, he writes in 1943 - it will not be for post-war peace and German Protestant reconstruction only; it will be for a new historical and civilizational epoch marked by expanded and unprecedented human powers.

In this setting, "world come of age," or "coming of age, ${ }^{14}$ has descriptive power that Bonhoeffer latches on to and keeps. Yet it cannot be what, at first blush, it would seem to be - a reference to moral maturity. Bonhoeffer is sitting in prison because the very nation that was teacher to the world in all things from philosophy and theology to science, medicine, and literature has gone mad. "World come of age" refers instead to moral accountability and responsibility. The person who has come of age, typically at 18 or 21 , is responsible for his or her actions, whether mature or not. Parents, or God, are no longer responsible for the child turned adult.

The phrase, however, is not "person come of age," it is "world come of age." Coming of age has gone global. It has done so in an epoch in which human beings collectively are accountable for heightened human knowledge and power that affects "the whole of earthly life" (a phrase from Ethics). For better and worse, nature is increasingly "organized" in accord with sovereign human design. Virtually all eco-systems are either already embedded as part of human systems or are profoundly impacted by them, whether in the atmosphere, the oceans, or across landmasses.

This greatly - and gravely - expanded knowledge and power is epistemological and theological as well as moral. It need not posit God as necessary to advancing either knowledge or power, and does not turn to a parental God for a bail-out when that knowledge and those powers fail, as they do and will. Here resides Bonhoeffer's critique of religion. The God of this new moment will not be God as a working hypothesis, the God-of-the-gaps. Nor will this be the rescuer God, God as deus ex machina. Not only can responsible persons get along quite well without these "Gods," but also turning to them is a moral cop-out. The God-of-the-gaps and the rescuer God belong to the dysfunctional religion of an earlier consciousness and era. In an epoch we now recognize as an era of planet-changing anthropogenic power, "claiming Christ" for "a world-come-of-age," or answering the question, "Who is Jesus Christ, for us, today," will need to take some other course. It will confront human power and knowledge so as to find God in what we do know, rather than in what we don't, and in problems that are solved, rather than only when and where we are vexed. Moral accountability and confession of sins will address the sins of

14 See especially LPP, 8 June 1933, 324-329. 
our strengths and powers, rather than our weaknesses only. If God and standing before God in the Anthropocene cannot be located at the heart of human power, accountability, accomplishment and failure, then God and morality are pushed to the far margins of what counts for the life of the world.

Can more be said about the fate of faith and God in the Anthropocene, given the direction of Bonhoeffer's thoughts?

The various approaches Bonhoeffer tries in Ethics, none of which was ever completed to his satisfaction, may register more than his abrupt pause seems to indicate. Of particular note is the late 1940 sketch of "Natural Life." The very first sentence is: "The concept of the natural has fallen into disrepute in Protestant ethics." ${ }^{15}$ A blistering critique of "the elimination of the category of the natural from Protestant thought" 16 then follows before a turn to the natural as the substantive basis for essential elements of an ethic: a notion of justice, human rights and the freedom of bodily life, natural rights and the life of the spirit, etc. ${ }^{17}$ Given his thesis about the nature-alienated origins of the world-shaping powers that have brought a new epoch with them, and given his sense of the spiritual and moral ineptitude that attends these aggressive powers, where Bonhoeffer might have gone with "the natural" as the basis for reconstructed and extended responsibility is a provocative, if necessarily open and unanswered, question. ${ }^{18}$

One thing is certain. Whatever the course of human responsibility is, and whoever its God in a world-coming-of-age, that course and God will be Earth-oriented and Earth-honouring. Bonhoeffer will have nothing whatsoever to do with otherworldly faith, even in a time of deep human trouble, a time of "trembling hands," "clenched teeth," ${ }^{19}$ and Earth's "distress," ${ }^{20}$ as well as a time when he must personally reckon with his family's distress and his own death. Whether in the depths of human-generated crises, or atop accomplishments, the prayer of those who rightly pray the first petition of the Lord's Prayer for the coming of God's kingdom on Earth is a prayer "of the most profound solidarity with the world" in which the church swears "oaths of fealty to the Earth." ${ }^{21}$ Fidelity to God is fidelity to Earth for

15 DBWE 6:171.

16 DBWE 6:172.

17 DBWE 6:178-218.

18 My thanks to Gary Simpson for suggesting this tie back into Ethics of Bonhoeffer's prison theology.

19 DBWE 10, 289.

20 DBWE 10, 378.

21 DBWE 10, 289. 
Bonhoeffer. It is also a faith that was commensurate with science's story of evolution, as he understood that.

There is more. While as a Barthian Bonhoeffer was suspicious of natural theology, he, like Luther, is emphatic about our nature as earth creatures whose very essence is to be that and no more. In his exegesis of Genesis 1-3, he writes that "Even Darwin and Feuerbach could not use stronger language than is used here. Humankind is derived from a piece of earth. Its bond with the earth belongs to its essential being. The 'earth is its mother'; it comes out of her womb." 22 This is a continuation of his earlier, equally emphatic, presentation on the foundations of Christian ethics (1929): "It is only through the depths of earth that the window of eternity opens itself up to us.... An ancient and profound old legend tells us about the giant Antaeus, who was stronger than all the men of the world. No one could defeat him until during one battle his adversary lifted him up off the ground; whereupon the giant lost the power that had flowed into him only from his contact with the earth. Those who would abandon the earth, who would flee the crisis of the present, will lose all the power still sustaining them by means of eternal, mysterious powers. The earth remains our mother just as God remains our father, and only those who remain true to the mother are placed by her into the father's arms. Earth and its distress - that is the Christian's Song of Songs." ${ }^{23}$ Evidently we will only save that which we recognize as our own being - Earth. Alienated from Earth, our powers turn destructive.

But back to the 1932 address. The battle is not only against nature, but also "against other human beings." "In the most essential sense his life means 'killing," Bonhoeffer says bluntly of the European. ${ }^{24}$ Western civilization, fragmented from the rest of nature in its core consciousness, destroys natural and human communities together in an exercise of collective power with few spiritual and moral constraints. Needless to say, Bonhoeffer rejects this kind of collective assertion and identity. His fascination with Gandhi at this time will continue as he (Bonhoeffer) grows convinced of the exhaustion of a viable European-American spirituality, ethics, and politics for an age that, for us, has evolved as the Anthropocene.

22 Creation and fall, DBWE, 76. The "earth is its mother" is a reference to Sirach 40:1b. Elsewhere at this time, in the 1932 address entitled, "Thy Kingdom Come! The Prayer of the Church-community for God's Kingdom on Earth," Bonhoeffer cites the exact words of this verse: earth "is the mother of us all." "Thy Kingdom Come!" is available in DBWE 10, 285-97.

23 "Basic Questions of a Christian Ethic," DBWE 10, 377-78.

24 DBWE 11, 252-53. 
This early analysis is deepened in Ethics where not only German fascism but also the Enlightenment tradition itself comes under critique. Bonhoeffer, ever the Prussian conservative, is deeply suspicious of the hubris exhibited "when big words are spoken about a new humanity, of a new world, a new society that will be created, and all this newness consists only in the annihilation of existing life." ${ }^{25}$ The lethal theme in this pretence is mastery that knows no limits as undertaken by autonomous humans in the name of freedom without constraint. ${ }^{26}$ Thus do we experience "the twinning of freedom and terror," "the upsurge of a terrible godlessness in human presumptions of god-likeness, ${ }^{27}$ the deification of humans who end up despising those who do not conform to their image. Ways of life that acknowledge no limits as they wield heightened human power are the backdrop for what happens next: the theologian working on Ethics as his magnum opus must undertake a new departure. Even the present war, and the Great War before it, is symptomatic of a deeper, broader civilizational crisis from which Christianity is not exempt. The new era requires, then, a deeper, more exacting, rethinking of faith and life than Ethics has thus far provided. In short, the theological-moral journey of "claiming Christ for a worldcome-of-age" moves, as it were, from a stock taking of the modern world into no less than a "Taking Stock of Christianity" itself (the first chapter of the new work). "What is Christian Faith, really?" Bonhoeffer asks (the second chapter).

Tellingly, "Taking Stock" begins with the insight of a deeply altered human presence - the coming of age of the human being" - while "What is Christian Faith, really?" moves in response to the very heart of faith, God.

The logic is clear. Bonhoeffer has concluded that world-come-of-age powers lack a viable faith and ethic to guide them ("the power of the soul is lacking"). He has also concluded that the God who is the working hypothesis, the "stopgap for our embarrassments," in short, the God of "religion," ${ }^{8}$ has been rendered "superfluous" in a world-come-of-age. So after a sub-section that links the two subjects to one another, "Worldliness and God," Bonhoeffer must ask straightforwardly, "Who is God?" In this new epoch, our experience of God will not be that of a "religious"

\section{DBWE 6:91.}

26 Here I am citing my own summary, from "The Ethics of Responsible Action," in The Cambridge Companion to Dietrich Bonhoeffer, John W de Gruchy, ed. (Cambridge University Press, 1999), 213.

27 This is Jean Bethke Elshtain's summary, interpreting Bonhoeffer. See Bonhoeffer for a New Day: Theology in a Time of Transition, John W de Gruchy, ed. (Eerdmans, 1997), 225.

28 "Outline for a Book," Letters and Papers from Prison, DBWE 8:500. 
relationship to God as some "highest, most powerful, and best being imaginable." Rather, our relationship to the transcendent is a life in "being-there-for-others," which is participation in the very being of Jesus, "the [Mensch] for others." "The transcendent is not the infinite, unattainable tasks, but the neighbour within reach in any given situation. God in human form!"29 "The human being living out of the transcendent." 30 A this-worldly life, a life of "Earth and its distress" as the "Christian Song of Songs," is life that experiences transcendent powers. The worldly finite bears the infinite.

For persons of Protestant faith, living out of the transcendent amid utterly thisworldly relationships in a new epoch next moves, again of logical necessity, to reinterpreting the biblical base points of theology - creation, fall, reconciliation, repentance, faith, vita nova, last things." ${ }^{31}$ Bonhoeffer, the systematic theologian, could not entertain matters more foundational than these.

How far he will go in reinterpreting the faith is signalled in a further sub-section that begins, "What do we really believe?" "I mean, believe in such a way that our lives depend on it?" He criticizes Barth and the Confessing Church for, in effect, hiding behind "the faith of the Church"' and the question of what we should believe. That is not sufficiently radical for the new epoch. Don't start with, say, the Apostles Creed, to ask what we "must" believe. Rather, what do we "really believe" such that we'd stake our existence on it. What way of life and meaning belong to the powers we wield in the world we have?

Put differently, as they are in the letter of 30 April, a "religious a priori" in human beings can no longer be assumed. While that a priori has been foundational to "nineteen hundred years of Christian preaching and theology," it may only be "a historically conditioned and transitory form of human expression." A different age and culture, possessed of a different epistemology, cosmology and consciousness [read: world-come-of-age], might well show that "the foundations are being pulled out from under all that 'Christianity' has previously been for us ..."32 The conclusion is that the task of Ethics - to construct a comprehensive ethic of responsible action - must, even for its own sake, now push reform beyond Bonhoeffer's own forays in the Ethics manuscripts to date. He must revisit, and renew, the most essential creedal elements of the faith, together with its practices. ("What does a church, a

29 "Outline for a Book," Letters and Papers from Prison, DBWE 8:501.

30 "Outline for a Book," Letters and Papers from Prison, DBWE 8:501.

31 "Outline for a Book," Letters and Papers from Prison, DBWE 8:502.

32 “Letter of 30 April, 1944," DBWE 8:362-33. 
congregation, a sermon, a liturgy, a Christian life, mean in a religionless world?" Bonhoeffer asks in the same letter.) $)^{33}$

These are not questions of despair or desperation for Bonhoeffer. His daily practice of devotion does not flag and he finds his new insights exhilarating. These questions simply belong to the relentless honesty that follows from insight into the profound changes and challenges posed by a new epoch.

Another Bonhoeffer essay, this one on the lessons learned in ten years of resisting The Third Reich, offers yet another premonition of Anthropocene reality. Here the attention is less the accurate description of the new era than it is the existential feel of living at a terrible moment of history. Here there are real overtones of loss and longing, if not despair.

In that Christmas gift to fellow resisters, one paragraph is entitled "Without Ground under One's Feet." Bonhoeffer first asks whether there has ever been a people in history who felt so little solid ground under their feet [as the resisters have], and to whom "every possible alternative open to them at the time" seemed "equally unbearable, senseless, and contrary to life?" 34 But after registering the resisters' experience of little ground and no good alternative, he asks whether this is their experience only, "Or rather, facing a great historical turning point, and precisely because something genuinely new was coming to be that did not fit with the existing alternatives, did the responsible thinkers of another generation ever feel differently than we do today?"35

The very next paragraph is "Who Stands Firm?" There every respected ethical alternative is emptied of authority by its failure to meet the evil of German fascism. In a brilliant parsing of all the moral options - the ethics of reason, duty, conscience, freedom, and virtuousness, even fanaticism - Bonhoeffer exposes their flaws. None provided sufficient grounds for effective responsibility. While this failure of the moral options may dovetail with Bonhoeffer's analysis of a world coming of age and a need to rethink Christian faith in every way, the emphasis lands on the experience of patriotic resisters who must live with the moral failure of their own German heritage and the demonstrated inadequacy of the respected moralities of their own culture.

33 "Letter of 30 April, 1944," DBWE 8:364.

34 "An Account at the Turn of the Year 1942-1943," Letters and Papers from Prison, DBWE $8: 38$.

35 "An Account at the Turn of the Year 1942-1943," Letters and Papers from Prison, DBWE $8: 38$. 
Small wonder, then, that a later paragraph asks, "Are We Still of Any Use?" It finishes with this question: "Will our inner strength to resist what has been forced on us have remained strong enough, and our honesty with ourselves blunt enough, to find our way back to simplicity and honesty?"36 Small wonder, too, that the very last paragraph, "The View from Below," finds Bonhoeffer in quest of a different angle of vision and starting point. While it is anchored in the experience of resistance, it takes the resisters beyond their own cherished, but deeply flawed, culture and heritage. In their quest for another Germany, Bonhoeffer finds it a matter of "incomparable value" that the resisters have "for once learned to see the great events of world history from below, from the perspective of the outcasts, the suspects, the maltreated, the powerless, the oppressed and reviled, in short from the perspective of the suffering." "Personal suffering is a more useful key" and "a more fruitful principle," it turns out, "than personal happiness." At least it is so "for exploring the meaning of the world in contemplation and action." ${ }^{37}$

"More fruitful" may be a synonym for "more truthful." The view "from below" gives a more truthful account of how the stories we live by and the systems that bind us together go dreadfully wrong. The unexpected gift of this perspective is to see the fault lines of the world in ways wilfully avoided in the ranks of the privileged. Truth available from below is truth obscured or resisted elsewhere. To gather it in is to make possible what is otherwise impossible; namely, "to do justice to life in all its dimensions." ${ }^{38}$ Building up responsibility at a "great turning point in history" will best proceed, will "more fruitfully" proceed, from the places where creation groans in travail.

In summary, we know what provoked Bonhoeffer to turn to ethics as his magnum opus, rather than systematic theology. It was his conviction that the moral grounds of modernity in the West were effectively spent. What seems to have happened in his prison insights on human power and a world come of age is that he sensed even his own efforts at a reconstructed ethic were inadequate. The goal - an ethic of responsible action - was correct. It remains. The emerging new epoch of human power was making clear, however, that a more fundamental theological and moral

36 “An Account at the Turn of the Year 1942-1943," Letters and Papers from Prison, DBWE 8:52.

37 “An Account at the Turn of the Year 1942-1943," Letters and Papers from Prison, DBWE $8: 52$.

38 “An Account at the Turn of the Year 1942-1943," Letters and Papers from Prison, DBWE $8: 52$. 
reform was needed. Ethics could not proceed until the new "Taking Stock" was completed.

We must leave Bonhoeffer here. His premonitions of Anthropocene reality are these. 1) An aggressive Western war-and-industry identity alienated from nature and fuelled by mastery that knows no limits as undertaken by autonomous humans in the name of freedom without constraint (to repeat our earlier formulation) has accompanied, even driven, gravely expanded human knowledge and power. 2) The reach of this human knowledge and power and its impact upon all earthly life has strained our ethical concepts to the breaking point. This sets in motion the need to reconceive human responsibility itself, both its nature and its scope. 3) There is no dialling back of history to some previous age, including the age of a religious a priori and the God of religion. For Christians, this means the constructive work entails no less than deep interrogation of faith's essential base points - Who is God? What do we really believe such that we would stake our lives on it? Who is Jesus Christ for us today when "today" is another epoch, even a non-analogous one? How to claim Christ for a world-come-of-age is the venture in front of us. 4) In an epoch where "everything depends on humankind," the constructive work of faith and the experience of Jesus Christ will be this-worldly and Earth-honouring. In a worldcome-of-age, transcendence, indeed God, is "the beyond in the midst of life." ${ }^{39}$

We belong to an epoch Bonhoeffer himself could not have seen. Namely, a new geological epoch and not simply a new historical one, itself effected by human powers he saw developing but with consequences he could not have imagined (e.g., climate change, mass extinction). Nonetheless, his sense for its causes and its trajectory was sound. So, too, was his sense for the fundamental theological and ethical task that the Anthropocene has placed in our hands. 